\title{
塗料原料とする魚油塩素化物の製造に関する研究一】I.
}

魚油塩素化物配合塗料を塗布した木片の燃焼温度について

\author{
鈴 木 康籍 \\ (1961 年 3 月 20 日受理)
}

\author{
PREPATION OF A COATING MATERIAL BY CHLORINA- \\ TION OF FISH OIL-XII. \\ TEMPERATURE DURING COMBUSTION OF A WOODEN PLATE \\ PAINTED WITH A COATING MATERIAL CONTAINING \\ A CHLORINATION PRODUCT OF FISH OIL
}

\section{Kosaku SuzukI}

The fire-retardative effect which was produced by dissolving the chlorination product of fish oil in commercial paints was tested. In order to test on transparent coating films, paints which are freely mixible with the chlorination product were used.

Wooden test plates were coated with ordinary paints mixed with or without the chlorination product. After the coatings perfectly dried up, coated sides of the plates were heated at $550^{\circ} \mathrm{C}$. for 180 seconds by an electric furnace. During the combustion of the test plates, the temperature of the burning surface was measured without stopping to heat by the furnance. Test plates coated with a paint containing the chlorination product remained at far lower temperature than the plates coated with ordinary paints did. In other words, the chlorination product has been found effective to give fire-retardative property to an ordinary paint. It should be dependent on practical uses how mach chlorination product is adequate to give sufficient fire-retardative property to a coating material.

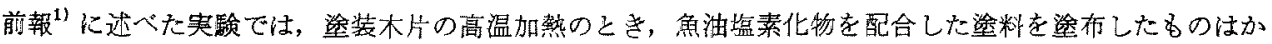

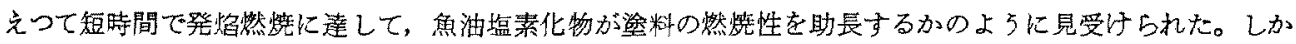

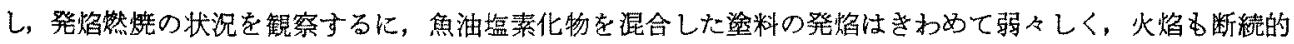
であり，加热中止と同特に消失したが，魚油塩索化物を混合しない塗料の発焰然烧は激烈であり，特にボイ 儿油の場合は篗発的な発焰を見た。この場合でさ完魚油塩素化物を混合したるのの発焰ははなはた徽弱なす のであつた。このように魚油塩素化物の防火性は肉眼的に観察されたが，塗料に魚油塩素化物を混合した場

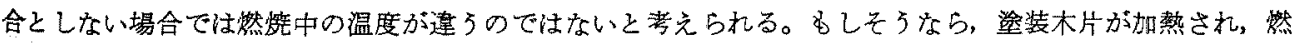

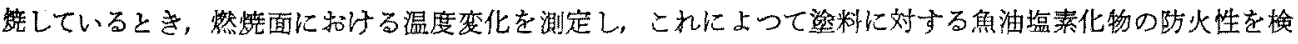
討することができるすのと考えて本実験を行なつたが，叙料の防火性を示すには発焰然焼に要する加熱時間

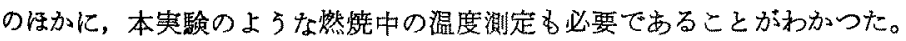

\section{実伢むよび結果}

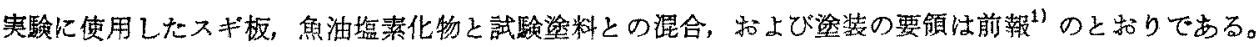

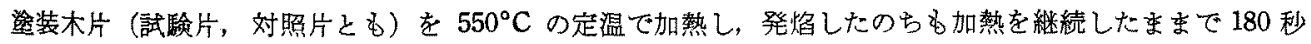

*東京水産大学沼津实翼埸 (Numazu Fish. Lab., Tokyo Univ. Fish., Numazu, Shizuoka Pref., Japan). 


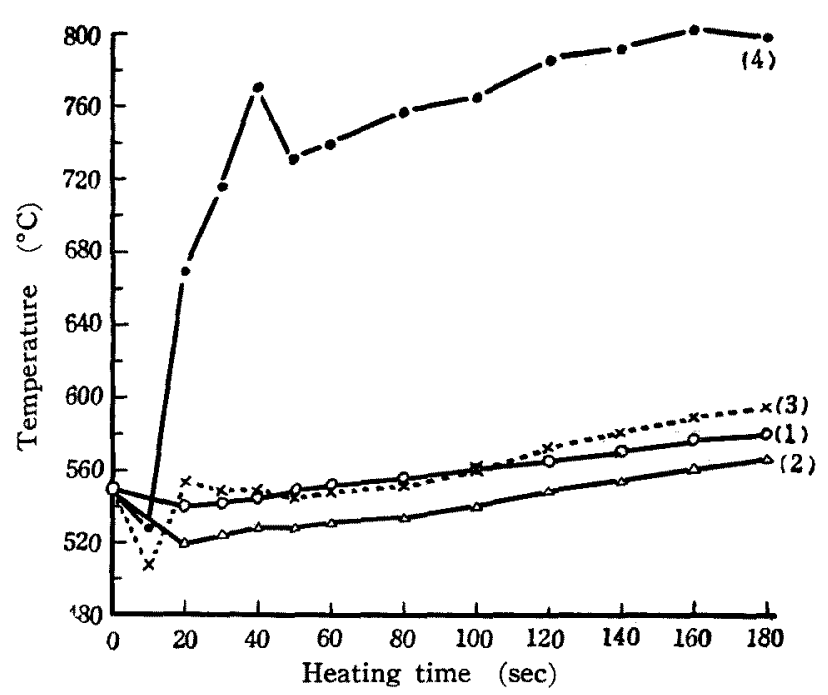

Fig. 1. Temperature during combustion of wooden plates painted with mixtures as indicated on Table 1.

Numbers are correspond with those of Table 1.

Table 1. Mixtures used for the experiment of Fig. 1.

\begin{tabular}{|c|c|c|c|}
\hline \multirow{2}{*}{ No. } & \multicolumn{2}{|c|}{ Composition of coating material } & \multirow{2}{*}{$\begin{array}{l}\text { Weight of film } \\
\text { coated on a } \\
\text { wooden plate }\end{array}$} \\
\hline & Boiled oil & $\begin{array}{l}\text { Chlorination product } \\
\text { of fish oil }\end{array}$ & \\
\hline (1) & $1 \mathrm{~g}$ & $1 \mathrm{~g}$ & $3.7 \mathrm{~g} / 100 \mathrm{~cm}^{2}$ \\
\hline (2) & $"$ & 2 & 3.6 \\
\hline (3) & $n$ & $2^{*}$ & 3.5 \\
\hline (4) & $"$ & 0 & 3.5 \\
\hline
\end{tabular}

* A chlorination product at an early stage of the author's study. Its melting point is $53 \sim 54^{\circ} \mathrm{C}$.

Melting point of the product of No. 1 and 2 is 220 $\sim 222^{\circ} \mathrm{C}$.
間然烇面の温度を測定した。ボイ油 ルの場合を Fig. 1 に示した。この 図の (1) (4) の番号は Table 1 の 番号に対応するるので, ホホル油と 魚油塩䇣化物との混合割合の区別を 示するのである。な拉，魚油塩素化 物の溶郕としてはなるべく不然性の むのという目的からテトラクロルエ チレンを使用した。Fig.1で見る と加熱初期に一時温度が降下してい るが、これはあらかでめ $550^{\circ} \mathrm{C} に$ 保持された電気炑の加熱部に，室温 にある塗装木片を急にセットするた めであり，また熱分解によつてはじ めは比較的低温のガスが発生するた めである。ここに発生した混合ガス のいかんによつて然焼中の温度が Fig. 1 の (1)〜 (4)のよ5になる。 （4）はボイル油のみを塗装した場合 であるから，激しく発焰然焼して直 ちに高温に達する。加熱を中止して も発陒然䭅は継続しだ。同図の（1) （3）の場合も 10 秒内外の加熱時 間で発焰燃焼を起したが，180 秒加 熱乙燃烧を続けて子，火焰の温度は $600^{\circ} \mathrm{C}$ に達しない。火焰の熱いは弱 く，もし加熱を中止（炉上り燃烧木 片を取りはづす)するならば，火烟 は瞬時にして消失する。同図 (2) に 和いては然烸中の加熱を中止しなく て当，火焰は 20 秒ぐらいしか継続

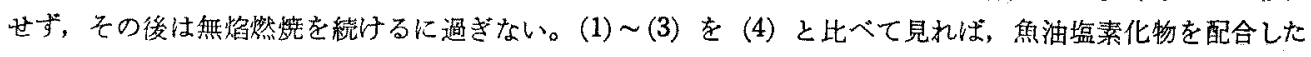
ボイル油が防火性となることが明睹にわかる。(1) と（2）の比較の上うに，魚油塩素化物の混合率が大とな

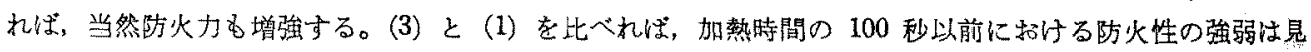
わけにくいが，加熱が長びくと（1）の汪うがすぐれていることがわかる。しかも，(1) の魚油塩素化物の混 合率は（3）の場合の半分であるから，(3) と同じ防火性を持たせるのに（1）の場合は半分の混合率でよい

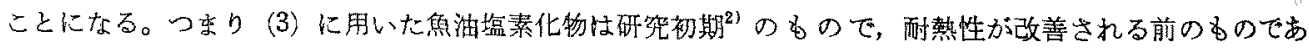

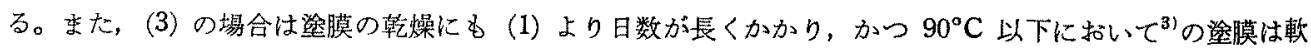

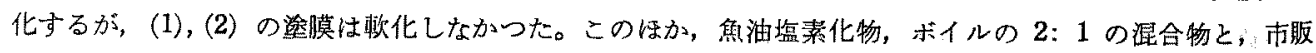
エンパラ 70, ホホイル油の 2: 1 の混合物, 拈よび市股の防火塗料につき，その防火性を比較するため， Fig. 1 のとを同样にして签装木片然焼中の温度を測定したが，結果は Fig. 2 のと括りで, 魚油塩素化物

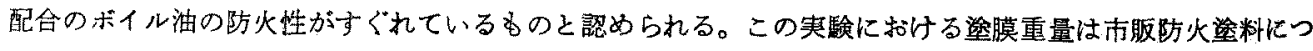

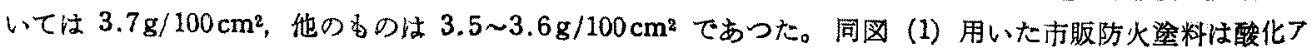




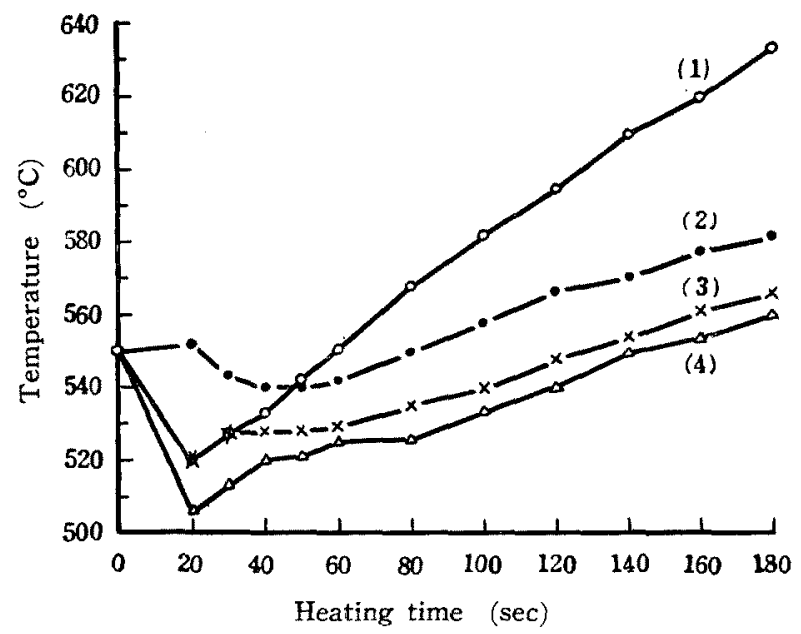

Fig. 2. Temperature during combustion of wooden plates painted with fire-retardative materials.

(1) ordinary commercial fire-retardative paint, "Chitanshiro" containing inorganic pigment.

(2) boiled oil mixed with commercial fire-retardative material "Empara-70".

(3) boiled oil mixed with a chlorination product of fish oil.

(4) Tin plates were used instead of wooden ones in the case of (3).

ンチモン，塩素化パラフィン，フタル酸樹脂を主成分とするもので，防火塗料としてはこく普通のるのであ

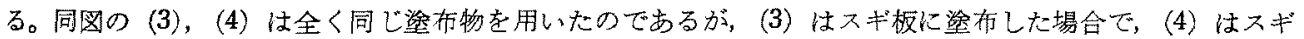

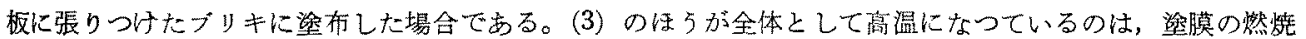
に対し，スギ板の然尭が影響しているためであるらと推察される。

ボイル油に対する魚油塩菜化物の防火効果が上述のよ5に整認されたので，他の市肘菬料について，淎料 1 に対し魚油塩素化物 2 の割合（重量比）で焦合したものと漉合しない㳂料につき，Fig. 1 ボイル油の場合

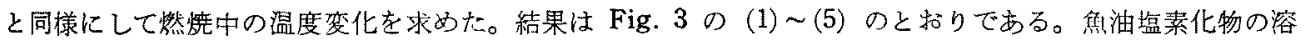
剂としてテトラタロルメチレンを使用し たのは前述同様であるが，塩化ビニール

Table 2. Weight of film coated on a wooden plate 樊料の場合はその溶解性の関係でトリク ロルエチレン 15 に対し酢酸ブチル1の 混合溶剤を用いた。各試験㳂料の盗布量 は Table 2 のと扣りである(染膜乾燥 後の重量を示)す。Fig. 3 の番号 (1) (5) は Table 2 の番号に対応する。 Fig. 3 を見ると，(2) のスパーワニス， (5) のフタル酸アルキッドに対する防火 效果は最多顕著であり，(4) のメラミン in the experiment of Fig. 3.

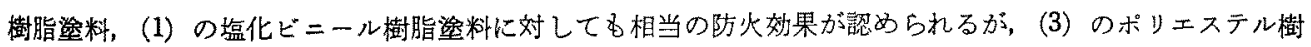
脂塗料に対しては防火性を附与する效果が不明暸である。 

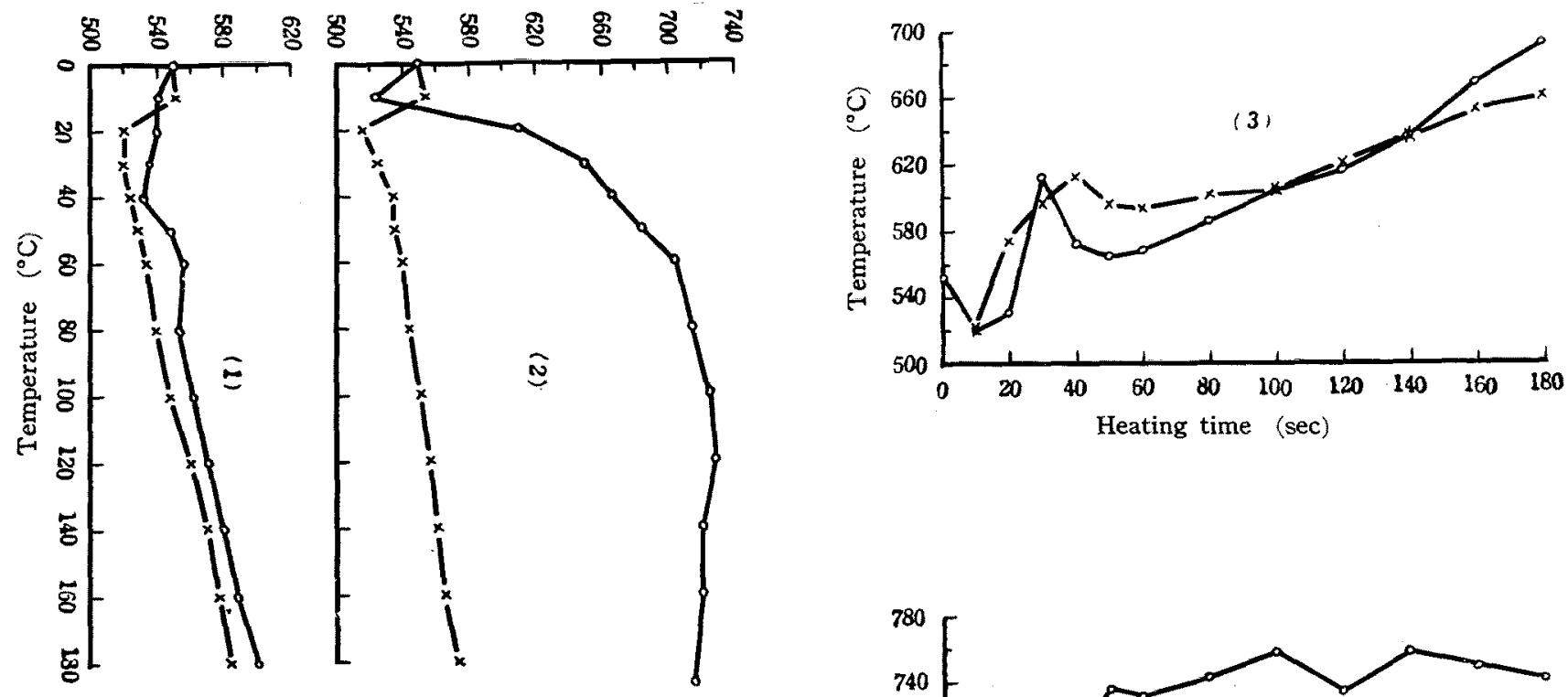

ริำ
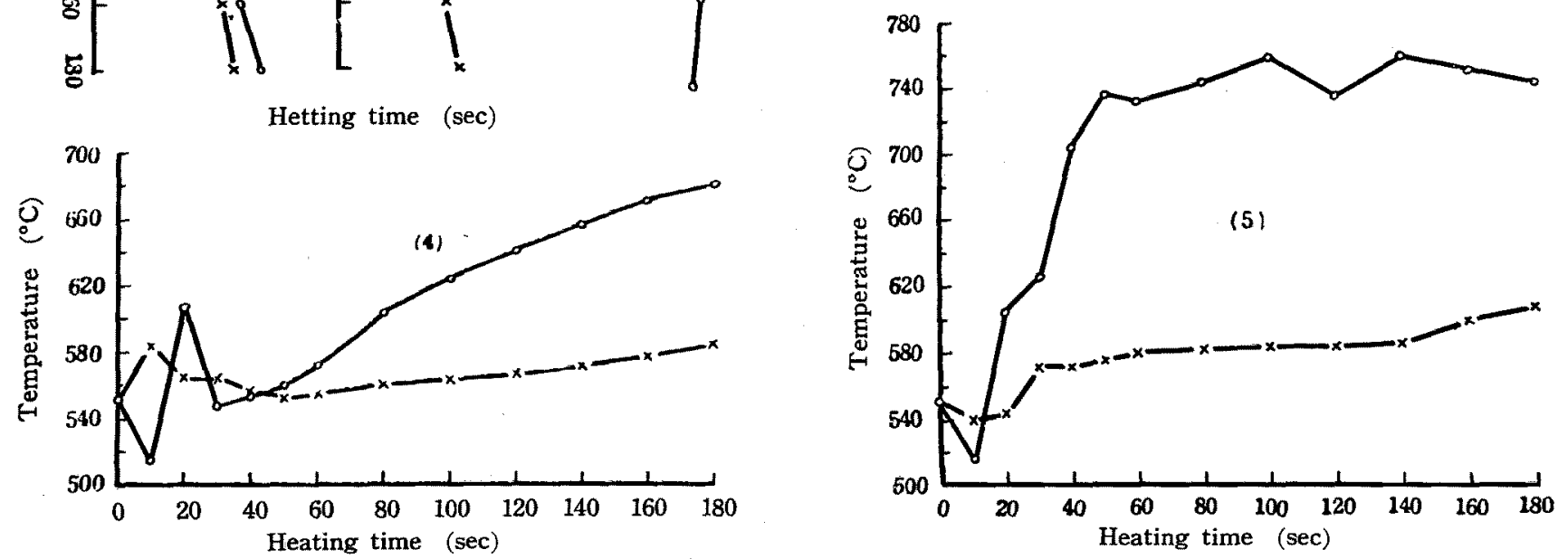

Fig. 3. Temperature during combustion of wooden plates painted with various kinds of coating material. $-x-x-$ test plate $\quad-0-O-$ control plate 


\section{考 察}

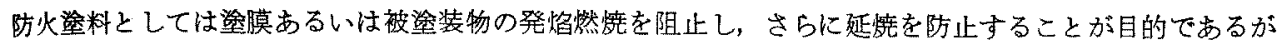
魚油塩素化物を混合した湦料時として前報" の上うに発焰しやすい埸合がある。しかし，この場合でも延

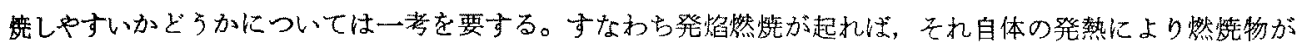

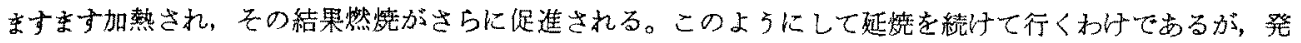

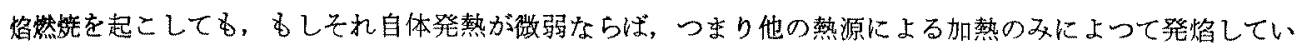
るだけならば，その加熱源の消隇とともに火炮も消隇するし，加熱を継続している場合でも，加熱され ている部分以外への延烧は起らない。本実験の上ろに, 焦油塩素化物混合の冾料は大体発焰然焼してる，然

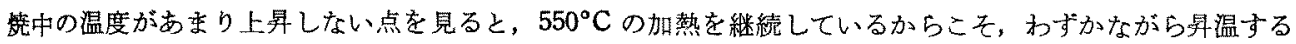

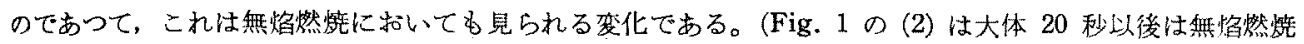
であるが $560^{\circ} \mathrm{C}$ 以上になつているし，同図 ${ }^{1)}$ b玨とんどこれと平行して年温している)。このよ5に魚油塩

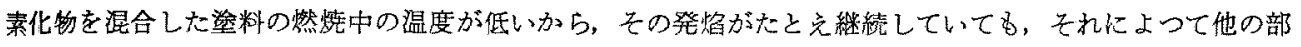
分へ延焼して行くことは考方られない。つまり，加熱されている部分のみの然烧で終り，延焼は防止される

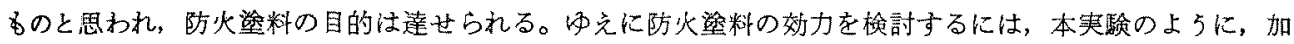
熱中の温度変化を調ベることが必要である。これらの検討の結果，魚油塩素化物は防火性淮料製造の一原料 としてはなはだ有奻なるのと諗められる。

總 括

魚油塩素化物と相溶性のある，透明被膜をつくる市販塗料に魚油塩素化物を混合し，これをスギ板に塗㭞

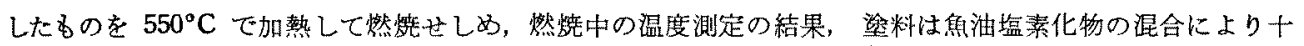

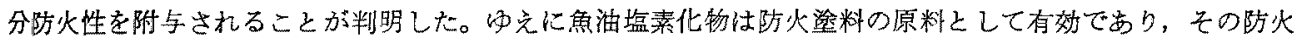
性注市眅塩素化パラフィンよりるすぐれている。

終りに，本研究に対し御指導をいたたいた東京工業大学舟木教授に心から感謝します。

文南

1）鈴木康策：本誌，27，581 (1961).

2) ——: —, 24, 45 (1958). 